\title{
On two sibling species of Dictyna (Araneae: Dictynidae) from Ukraine and Caucasus
}

\author{
Yuri M. Marusik \& Seppo Koponen
}

\begin{abstract}
Marusik, Yu. M. \& Koponen, S. 2017: On two sibling species of Dictyna (Araneae: Dictynidae) from Ukraine and Caucasus. — Entomol. Fennica 28: 4148.
\end{abstract}

Dictyna ottoi $\mathbf{s p .} \mathbf{n}$. is described based on specimens of both sexes collected in Azerbaijan. The new species is closely related to $D$. armata Thorell, 1875, a species described from Southern Ukraine. Detailed illustrations are provided for both species. Dictyna armata has never been illustrated before. Both species, together with $D$. uncinata Thorell, 1856, form the uncinata species group. Distribution records of the two sibling species are mapped.

Yu. M. Marusik, Institute for Biological Problems of the North RAS, Portovaya Str. 18, Magadan, Russia and Department of Zoology \& Entomology, University of the Free State, Bloemfontein 9300, South Africa; E-mail: yurmar@mail.ru S. Koponen, Zoological Museum, Department of Biology, University of Turku, FI-20014 Turku, Finland; E-mail: sepkopo@utu.fi

Received 20 September 2016, accepted 13 October 2016

\section{Introduction}

Dictyna Sundevall, 1833 is the largest genus of the family Dictynidae with 121 species (WSC 2016). However, it is rather poorly studied. Forty-one species are known from females only, and 11 by males, and some species lack any figures. Nearly half the species are known from a single entry in the WSC (2016). The genus has been revised broadly only in the Nearctic (Chamberlin \& Gertsch 1958), but the endogyne was not illustrated for any species.

While trying to redescribe Thorell's (1875a, b) type species from Southern Ukraine, which were never illustrated, we found a species, $D$. armata, with an unusually large tibial outgrowth and posterior tip of conductor that was unknown in Palaearctic species. Searching the dictynid material from the Caucasus, we found species with a similarly large tibial outgrowth and large poste- rior tip of conductor. A comparison of types of D. armata described from Southern Ukraine and specimens from Azerbaijan revealed that the species are not conspecific. The main goals of this paper are to provide an illustrated description of D. armata and a description of a new species from the south Caucasus.

\section{Materials and methods}

The specimens were photographed with a Canon EOS 7D camera attached to an Olympus SZX16 stereomicroscope and Pro-Microscan camera attached to the Olympus BH-2 at the Zoological Museum, University of Turku, Finland. Digital images were montaged using CombineZP and Helicon focus 3.10 image stacking software. Epigynes were cleared in a $\mathrm{KOH} /$ water solution until soft tissues were dissolved. The illustrations 
of $D$. armata were made by the first author over 25 years ago, when digital photography was not developed, and therefore $D$. armata misses habitus photographs. The photographs were taken in dishes with cotton or dark fabric on the bottom to hold the specimens in position.

All the measurements are given in millimeters. The lengths of leg segments were measured on the dorsal side.

The terminology follows Marusik and Penney (2010) and Marusik and Fritzén (2011) with some modifications.

Museums: NHRS $=$ Swedish Museum of Natural History (Stockholm), ZMMU = Zoological Museum, Moscow State University, Russia.

\section{Taxonomy}

\subsection{Dictyna ottoi sp. n. (Figs. 1, 2, 4)}

Material examined. Holotype $\widehat{\jmath}$ : Azerbaijan, some $10 \mathrm{~km} \mathrm{~W}$ of Astara Village, Isti-Su, 38 $27^{\circ}$ N 48 $47^{\prime}$ E, on the border with Iran, 25.IV.2001, Yu. M. Marusik leg. (ZMMU). Paratypes: $4 \AA 8$ ㅇ $4 \mathrm{j}$, same data as holotype (ZMMU); $1 \lambda$, Azerbaijan, Gabala (Qabala) District, Bum Town, 4058'53" N 4750'45” E, 5.VI.2001, E. Huseynov leg. (ZMMU); 1 , , Azerbaijan, Altiagach Village, $40.852055^{\circ} \mathrm{N}, 48.936559^{\circ} \mathrm{E}$, 15.VI.1980, P. Dunin leg. (ZMMU).

Diagnosis. The new species differs from $\mathrm{Pa}-$ laearctic Dictyna, except D. armata and D. uncinata Thorell, 1856, by a dorsal tibial outgrowth that is longer than the tibia, a large posterior tip of conductor, which is longer than the patella, and a swollen patella. Other species have a very short tibial outgrowth or one that is not longer than the tibial diameter, a small posterior tip of conductor that is shorter than the patella, and the patella is not swollen. Males of $D$. ottoi sp. n. differ from those of $D$. armata by the posterior conductor tip, which is thick in lateral view in the new species (Fig. 2d) and sickle-like and gradually tapering in D. $\operatorname{armata}$ (Fig. 3b). The new species differs from D. uncinata by having a much larger tibial outgrowth and posterior tip of conductor (cf. Figs. $2 b-d$, and 277c-d in Almquist 2006). Females of the new species differ from all other Palaearctic species except $D$. uncinata Thorell, 1856 and $D$. armata by well-defined copulatory openings spaced by more than 2 diameters apart and by a lack of sulci. Other species have poorly defined (without distinct margins) copulatory openings spaced less than one diameter apart and have a pair of sulci. Dictyna armata females can be distinguished from the new species by closer together copulatory openings (cf. Figs. 2e-g and $3 \mathrm{c}-\mathrm{d})$, a round receptacle $(R e)$ vs transverse ovoid receptacle and more divergent copulatory ducts. Differences between females of D. ottoi $\mathbf{s p}$. n. and $D$. uncinata are less distinct. Epigynes of these two species are indistinguishable, but the species can be separated by the shape of the chamber in the endogyne, which is triangle in D. ottoi sp. n. and oval in D. uncinata.

Description. Male (holotype). Total length 2.17. Carapace 1.07 long, 0.79 wide, 0.36 high. Carapace almost uniformly brown with darker pigmentation around fovea. Legs and palps light brown, without annulations. Chelicera concave in lateral view (Fig. 2a). Abdomen with a pattern of a dark rectangular spot in the anterior $1 / 3$ and a series of chevrons of different widths, with background pigmentation comprising translucent white guanine spots (Fig. 1c-d); sides uniformly brown. Measurements of palp and leg segments given in Table 1. Palp as in Fig. 2b-d; femur small, shorter than cymbium and thinner than patella; patella as wide as long, swollen in comparison to femur. Tibia strongly bent, with large dorso-basal outgrowth $(D o)$ bearing 2 ctenidia $(C t)$, and a broad retrolateral apophysis $(R a)$; dorsal outgrowth longer than tibia; cymbium wide, with short anterior part (tip). Conductor with thin anterior arm $(A a)$ terminating at about the 10 o'clock, posterior arm $(\mathrm{Pa})$ very massive and bent several times at tip $(P t)$, tip longer than tibia; base of embolus $(\mathrm{Be})$ large, its height subequal to $2 / 3$ of bulb length; spermophore runs along edge of base; embolus long, whip-like, with unmodified tip, beginning at about the $9 \mathrm{o}$ 'clock position.

Female. Total length 2.43. Carapace 1.03 long, 0.71 wide, 0.43 high. Colouration and body pattern same as in male, but carapace slightly darker (Fig. 1a-b). Measurements of appendages given in Table 2. Epigyne as in Fig. 2e-g; densely covered with hairs, copulatory openings $(C p)$ distinct as oval dark spots, separated by almost 3 diameters, openings almost round, sulci absent. Copulatory opening leads to large atrium $(\mathrm{Ca})$ 


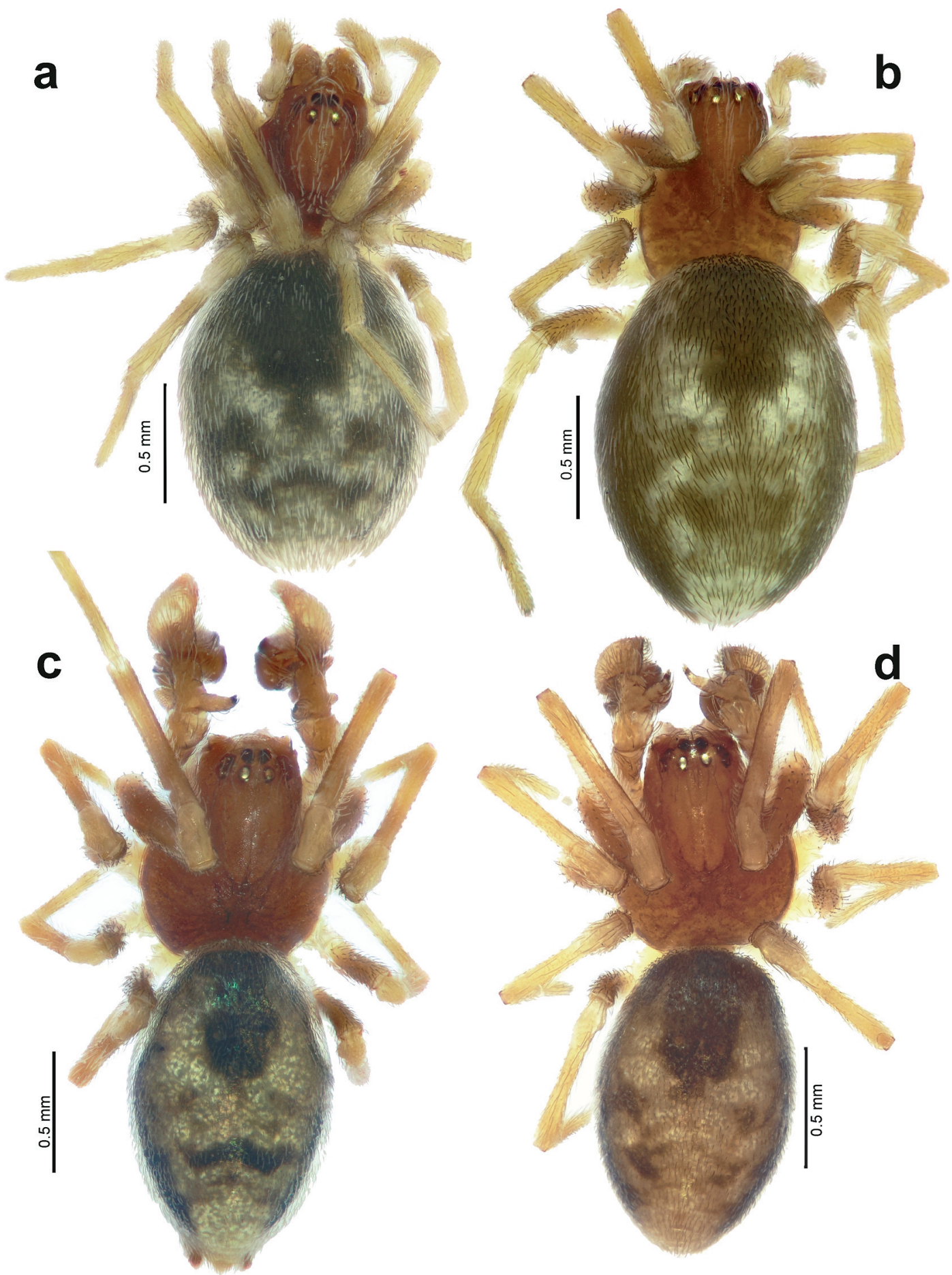

Fig. 1. Habitus of Dictyna ottoi sp. n. - a, b. Female. - c, d. Male.

with weakly sclerotized walls; atrium terminates into triangular heavily sclerotized chamber $(T c)$, copulatory ducts $(C d)$ short, beginning at trian- gle-shaped chamber and terminating in strongly sclerotized receptacles $(R e)$. Each receptacle is connected to a large membranous sack $(M s)$. 

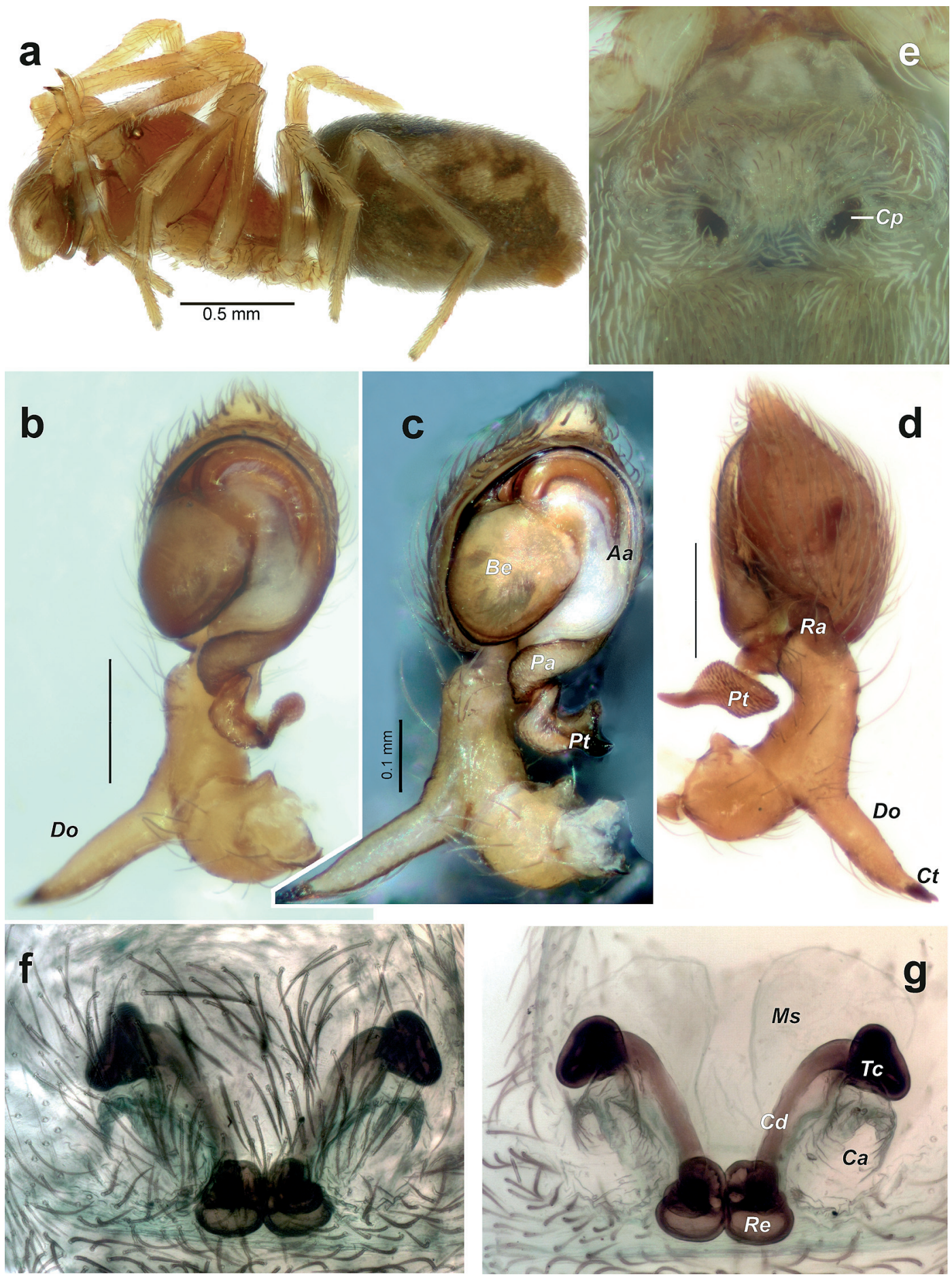

Fig. 2. Habitus and copulatory organs of Dictyna ottoi sp. n. - a. Male habitus, lateral view. - b, c. Male palp, ventral and ventro-prolateral view. - d. Male palp, retrolateral view. - e. Intact epigyne, ventral view. $-\mathrm{f}$, g. Macerated epigyne, ventral and dorsal view. Scale $=0.2 \mathrm{~mm}$ if not otherwise indicated. Abbreviations: $A a$, anterior arm; $B e$, base of embolus; $C a$, atrium; $C d$, copulatory duct; $C p$, copulatory opening; $C t$, ctenidia; $D o$, dorso-basal outgrowth; $M s$, membranous sack; $P t$, tip of conductor; $R a$, retrolateral apophysis; $R e$, receptacle; $T c$, triangle chamber. 
Table 1. Segment lengths of pedipalp and legs (I-IV) in male Dictyna ottoi sp. $\mathbf{n}$. Abbreviations: Fe, femur; Pa, patella; Ti, tibia; Mt, metatarsus; Ta, tarsus.

\begin{tabular}{lllllll}
\hline & Fe & Pa & Ti & Mt & Ta & Total \\
\hline Palp & 0.36 & 0.21 & 0.3 & - & 0.49 & 1.36 \\
I & 0.93 & 0.29 & 0.81 & 0.67 & 0.43 & 3.13 \\
II & 0.8 & 0.26 & 0.63 & 0.57 & 0.4 & 2.66 \\
III & 0.64 & 0.24 & 0.54 & 0.59 & 0.33 & 2.34 \\
IV & 0.71 & 0.26 & 0.54 & 0.59 & 0.33 & 2.43 \\
\hline
\end{tabular}

Table 2. Segment lengths of pedipalp and legs (I-IV) in female Dictyna ottoi sp.n. Abbreviations: Fe, femur; Pa, patella; Ti, tibia; Mt, metatarsus; Ta, tarsus.

\begin{tabular}{lllllll}
\hline & Fe & Pa & Ti & Mt & Ta & Total \\
\hline Palp & 0.29 & 0.17 & 1.21 & - & 0.3 & 1.97 \\
I & 0.83 & 0.3 & 0.61 & 0.59 & 0.4 & 2.73 \\
II & 0.71 & 0.3 & 0.5 & 0.5 & 0.36 & 2.37 \\
III & 0.69 & 0.29 & 0.4 & 0.4 & 0.33 & 2.11 \\
IV & 0.77 & 0.29 & 0.57 & 0.53 & 0.31 & 2.47 \\
\hline
\end{tabular}

Variation. Abdominal pattern slightly variable, as shown in Fig. 1a-d.

Distribution. The new species is known only from three localities in Azerbaijan (Fig. 4), although it probably occurs in adjacent Georgia. A sibling species, D. armata, which lacks any illustrations, has been reported several times from Georgia. Because D. ottoi sp. n. and D. armata are very similar, it is expected that they are easily confused.

Etymology. The species is named after our colleague and friend Stefan Otto (Leipzig, Germany) who has created a very detailed and useful website on Caucasian spiders.

\subsection{Dictyna armata Thorell, 1875 (Figs. 3, 4)}

Dictyna armata Thorell, 1875a: 72 (さ); Thorell, 1875b: 74 (ぷㅇ).

Material examined. Holotype $\widehat{\jmath}$ from "Jekaterinoslaw (A. von Nordmann)" [=Yekaterinoslav $=$ Dnepropetrovsk $=$ Dnipropetrovs' $k=$ cur rently Dnepr] in NHRS together with $3+$ from the same locality (Collectio Thorell 91/97).

Diagnosis. This species can be confused with D. ottoi $\mathbf{s p}$. n. from which it differs by having a more swollen male palpal patella (cf. Figs. $2 \mathrm{~d}$ and 3b), a sickle-like conductor tip (Fig. 3b) vs large and bent (Fig. 2b-d) and long, transverse ovate receptacles (Fig. 3c-d) vs globular (Fig. 2g-f). Dictyna armata is also similar to $D$. uncinata, but can be distinguished by a longer tibial outgrowth (as long as the tibia vs two times shorter than the tibia), a long sickle-like conductor tip vs short, and an oval receptacle vs round.

Description. Described by Thorell (1875a, b). Here we provide only illustrations of the copulatory organs. The male palp is as in Fig. 3a-b; femur short, almost as short as patella, and as long as tibial outgrowth; patella swollen, thicker than femur and tibia; tibia long, bent, with long dorsobasal outgrowth (Do) slightly longer than tibia and broad lamella like retrolateral apophysis $(R a)$; cymbium with short tip. Conductor with short and thin anterior arm $(A a)$ terminating at about the 12 o'clock position, and a large sicklelike tip of posterior arm $(\mathrm{Pa})$; base of embolus $(B e)$ large, almost as long as bulb; embolus originates about at the 10:30 o'clock position, filamentous. Epigyne as in Fig. 3c-d; copulatory openings $(C p)$ with strongly sclerotized mesal margins, separated by about 5 diameters; opening leads to a small, conical atrium $(\mathrm{Ca})$ with weakly sclerotized walls; copulatory ducts $(C d)$ straight 

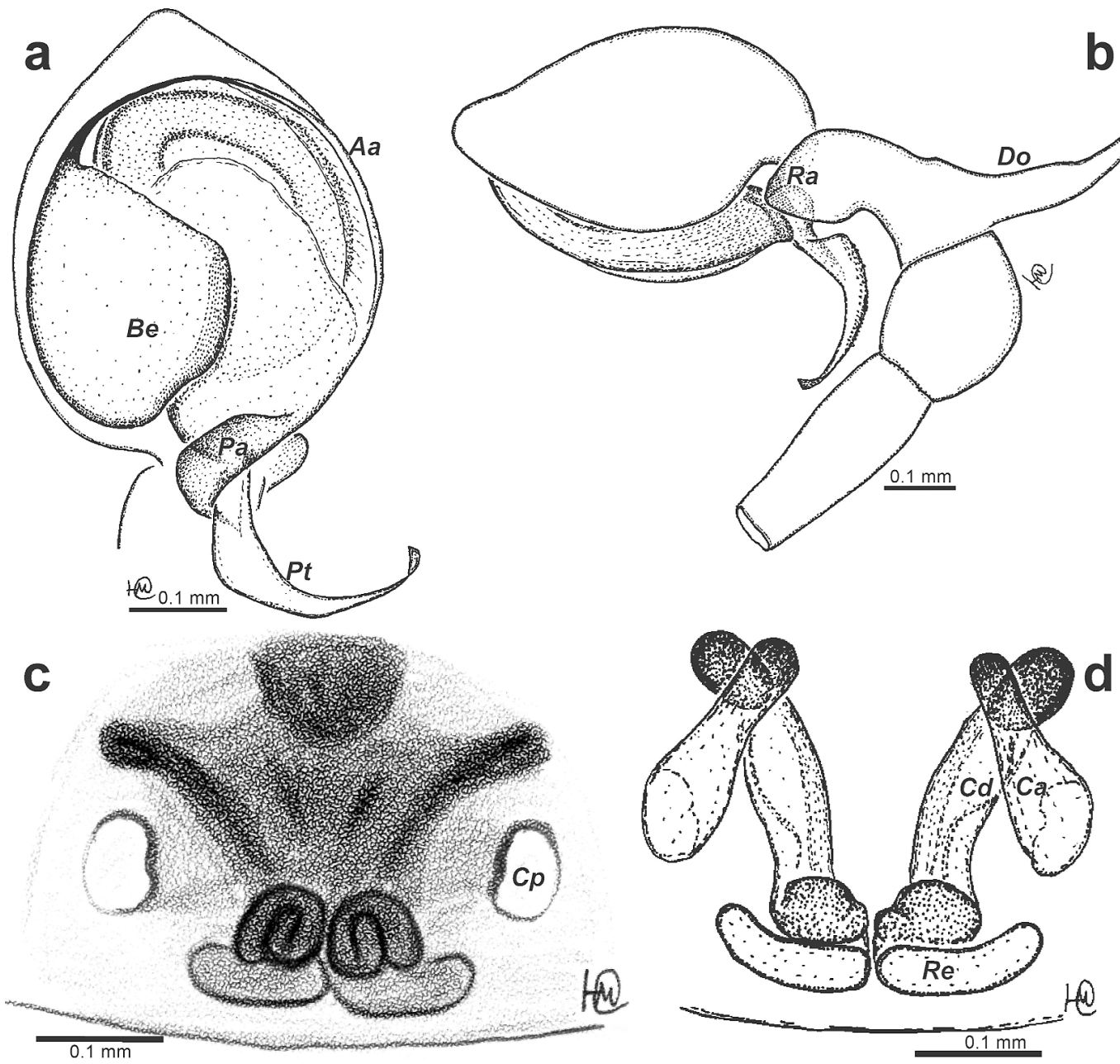

Fig. 3. Copulatory organs of Dictyna armata. - a, b. Male palp, ventral and retrolateral view. - c, d. Epigyne, ventral and dorsal view. Abbreviations: $\mathrm{Aa}$, anterior arm; $\mathrm{Be}$, base of embolus; $\mathrm{Ca}$, atrium; $\mathrm{Cd}$, copulatory duct; $C p$, copulatory opening; $D o$, dorso-basal outgrowth; $P a$, posterior arm; $P t$, tip of conductor; $R a$, retrolateral apophysis; $R e$, receptacle.

and short; receptacles $(R e)$ long, transverse ovoid.

Distribution. The species was reported from the vicinity of Dnipro and Odessa in Ukraine (Thorell 1875a, b) and from Gelati in central Georgia (Kulczyński 1895) (Fig. 4). Several reports of this species from Georgia by Mcheidze (see Otto 2015) apparently refer to Kulczyñski's record. It is very likely that the Georgian records refer to $D$. ottoi $\mathbf{s p .} \mathbf{n}$.

Remarks. The original description includes only the male. Thorell (1875b) described both sexes on additional material from Odessa, from where he had one male and several females. The females were assumed to be conspecific with the male, although Thorell could not with certainty distinguish them from $D$. uncinata.

Lehtinen (1967: 229) placed this species in the D. uncinata species group and indicated that he studied the male (or males) from the Zoological Museum, University of Helsinki. We were not able to locate this specimen, which probably was from Odessa.

\section{Discussion}

Dictyna armata, D. ottoi sp. n. and D. uncinata are closely related and form a distinct species 


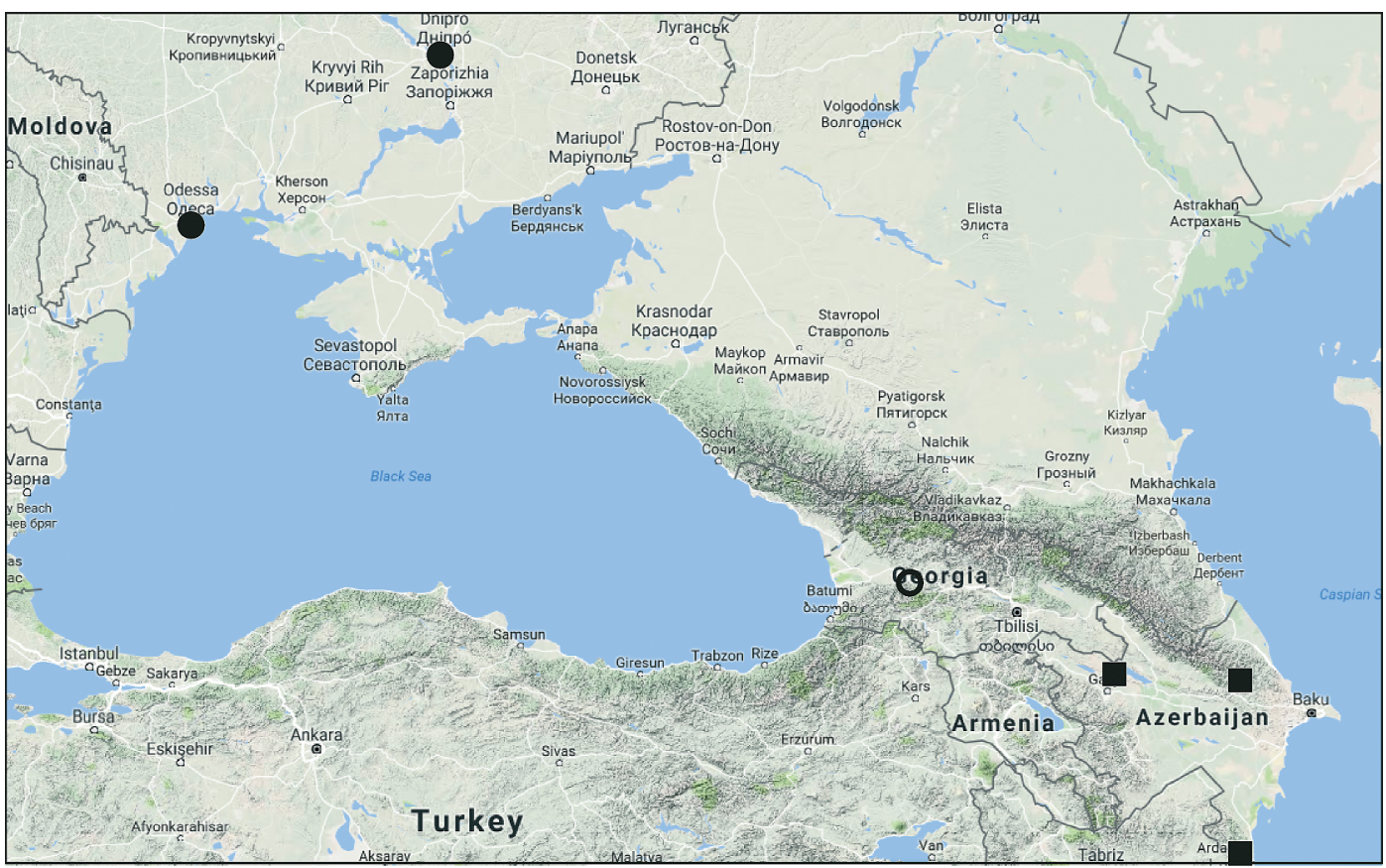

Fig. 4. Distribution records of Dictyna ottoi sp. $\mathbf{n}$. (square) and $D$. armata (circle). Open circle refers to the literature record of $D$. armata that may refer to $D$. ottoi sp. $\mathbf{n}$.

group. Lehtinen (1967) was the first to recognize this species group. All three species have large dorsal tibial outgrowths on the male palpi, longer than the tibial width, bent palpal tibiae, a large base of the embolus, widely separated copulatory openings and lack epigynal sulci.

A large, similarly shaped dorsal tibial outgrowth is known from several unrelated Nearctic species: D. bellans Chamberlin, 1919, D. calcarata Banks, 1904, D. cholla Gertsch et Davis, 1942, D. formidolosa Gertsch et Ivie, 1936, D. gloria Chamberlin \& Ivie, 1944 and D. longispina Emerton, 1888. However, these species all lack the bent male palpal tibia, two species that have a long palpal tibia, D. bellans and $D$. longispina, have a retrolateral spine unknown in other Dictyna, a strong anterior spine on the male chelicera and females have a very wide epigastral furrow (Chamberlin \& Gertsch 1958: pl. 16, figs. 1,6). Other similar species have either a short palpal tibia or a small embolic base, lack the massive tip of the posterior arm of the conductor and have closely spaced copulatory openings with distinct epigynal sulci. There are also three Palaearctic species with an enlarged tibial outgrowth, D. felis Bösenberg et Strand, 1906, D. foliicola
Bösenberg et Strand, 1906 and D. ubsunurica Marusik et Koponen, 1998, but the outgrowth is significantly smaller and similar to that of $D$. uncinata. The bulbs in these three Palaearctic species also differ from these in $D$. ottoi $\mathbf{s p .}$. and $D$. armata by having a small embolic base located almost in the center of the bulb (cf. Dunin 1984: figs. 11-2 and 15-16; Marusik \& Koponen 1998: figs. 18-19).

Acknowledgements. We thank Elchin Huseynov, Natalia Snegovaya and Khalid Aliev (all from Baku, Azerbaijan) for help organizing the expedition to Azerbaijan. Special thanks to Elchin Huseynov and Kirill Mikhailov (ZMMU) for giving us specimens considered here as paratypes of the new species. Torbjörn Kronestedt (NHRS) allowed us to study the types of D. armata. We thank also two anonymous reviewers for valuable comments. English of the final draft was kindly checked by Sarah Crews (Californian Academy of Sciences, San Francisco, USA).

\section{References}

Almquist, S. 2006: Swedish Araneae, part 2-families Dictynidae to Salticidae. - Insect Systematics \& Evolution, Supplement 63: 285-601.

Chamberlin, R. V. \& Gertsch, W. J. 1958: The spider family Dictynidae in America north of Mexico. - Bulletin 
of the American Museum of Natural History 116: 1152.

Dunin, P. M. 1984: (Materials on the spider fauna from the Far East (Arachnida, Aranei). 2. Section Cribellatae.) — In: Lehr, P. A. (ed.), Fauna and ecology of insects in the south of the Far East: 141-146. Dal'nevostochnyi Nauchnyi Tsentr Akademii Nauk SSSR, Vladivostok. 152 pp. [In Russian.]

Kulczyński, W. 1895: Araneae a Dre G. Horvath in Bessarabia, Chersoneso Taurico, Transcaucasia et Armenia Russica collectae. - Természtrajzi Füzetek 18:3-38.

Lehtinen, P. T. 1967: Classification of the cribellate spiders and some allied families, with notes on the evolution of the suborder Araneomorpha. - Annales Zoologici Fennici 4: 199-468.

Marusik, Yu. M. \& Fritzén, N. R. 2011: On a new Dictyna species (Araneae: Dictynidae) from the northern Palaearctic confused with the East Siberian D. schmidti Kulczyński, 1926. — ZooKeys 138: 93-108.

Marusik, Yu. M. \& Koponen, S. 1998. New and little known spiders of the subfamily Dictyninae (Araneae, Dictynidae) from South Siberia. - Entomological Problems 29(2): 79-86.

Marusik, Yu. M. \& Penney, D. 2010: Conformation of the male palp in some spiders belonging to the RTA-clade and problems in taxonomy: 272-276. - Book of Abstracts, $18^{\text {th }}$ International Congress of Arachnology 2010, Siedlce, Poland. 506 pp.

Otto, S. 2015: Caucasian Spiders. A faunistic database on the spiders of the Caucasus. Version 1.4.3. URL http://caucasus-spiders.info/ (Site visited on $12 \mathrm{Sep}-$ tember, 2016).

Thorell, T. 1875a: Verzeichniss südrussischer Spinnen. Horae Societatis Entomologicae Rossicae 11:39-122.

Thorell, T. 1875b: Descriptions of several European and North African spiders. - Bihang till Kongliga Svenska Vetenskaps-Akademiens Handlingar 13(5): 1-203.

WSC 2016: World Spider Catalog. Natural History Museum Bern, version 17.5. URL http://wsc.nmbe.ch (Site visited on 12 September, 2016). 